\title{
Analytical Study of Household Consumers' Food safety Awareness level Regarding Milk and Milk products in Khartoum - Sudan
}

Mubark Y.H. ElnouR ${ }^{1}$, Nahid M.T.Fawi ${ }^{2}$ and Adil M. A. Salman ${ }^{3 *}$

${ }^{1}$ Researcher, University of Bah
${ }^{2}$ Associate Professor, University
Article History
Received: 09.10 .2020
Accepted: 27.10 .2020
Published: 11.11 .2020
Journal homepage:
https://www.easpublisher.com

\section{Article History}

A

ccepted: 27.10 .2020

: 11.11 .2020

https://www.easpublisher.com/easjnfs

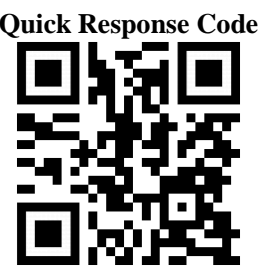


of the product [12] where consumer satisfaction in developed countries has transformed into a more daunting task for producers due to increasing critical and varied demands of consumers regarding food selection thus resulting in both vertical and horizontal quality differentiation [3].

The importance of this research arises from the fact that milk and milk products are of high demand and priority in Sudanese food culture implying the fact that food safety awareness among consumers should be analyzed thoroughly.

The objectives of this study were to assess consumers' awareness regarding food safety and the factors affecting their purchase decision; to analyze food safety practices performed by consumers' at the point of product purchase and to profile consumers' food safety knowledge.

\section{Materials ANd Methods}

This study was performed in Khartoum State, during the year 2020; research was based on primary data collection using a cross-sectional questionnaire that was designed to meet the objectives of the study. Personal interviews were performed with consumers under research to collect the primary data.
A stratified random sample of 150 consumers comprised the sample of the study where respondents were selected from various parts of Khartoum StateSudan. Stratification criteria included that the respondents should be family households who purchased and consumed fresh milk and/or processed milk products.

Collected data was further analyzed using the statistical package for social science (SPSS) version 21.0 to obtain frequency of distribution in addition to Chi- square values for certain variables under study.

\section{RESUltS AND DiscusSiON}

Upon analyzing the demographic profile of consumers under study almost one third $34.7 \%$ ranged between the ages 36-45 years. As for education level $64.7 \%$ were of intermediate and secondary education whereas $35.3 \%$ were university graduates. As for type of milk purchased most of the respondents $82.7 \%$ assured purchasing fresh raw milk in comparison to $17.3 \%$ who purchased processed milk. Such a result indicates strong consumer preference for raw milk a fact that should be taken into consideration when addressing food safety hazards that could affect consumers. A result that aligns with Fawi \& Abdalla [13] where that the majority of consumers in Khartoum State preferred fresh milk $88.7 \%$ compared by $42.0 \%$ who preferred processed milk. Table 1

Table-1: Demographic respondents' parameters; type of milk purchased

\begin{tabular}{|l|c|}
\hline \multicolumn{1}{|c|}{ Item Age of respondents } & $\%$ \\
\hline $20-35$ & 22.7 \\
\hline $36-45$ & 34.7 \\
\hline $46-55$ & 19.3 \\
\hline$<55$ & 23.3 \\
\hline \multicolumn{2}{|c|}{ Respondents educational level } \\
\hline Intermediate & 37.35 \\
\hline Secondary & 27.35 \\
\hline University graduates & 35.3 \\
\hline Post graduate & 00.0 \\
\hline \multicolumn{2}{|c|}{ Type of milk purchased } \\
\hline Fresh raw milk & 82.7 \\
\hline Processed milk & 17.3 \\
\hline
\end{tabular}

When studying purchase source of fresh raw milk $46.8 \%$ of the respondents preferred local groceries, $22.6 \%$ preferred purchasing from milk men vendors, $16.1 \%$ purchased from pickup vendors while $14.1 \%$ purchased directly from farms. Such a result reveals level of trust variation among consumers where it is clear that local groceries distributed within houses hold most preference for milk purchase, this could be attributed to convenience of place and consumers good link with sales man in such groceries. In India the emergence of modern milk marketing chains is posing stiff competition for the existence of traditional milk market agents, however, the basic structure of milk production and marketing is not likely to change significantly in the near future and therefore, the dominance of traditional milk market chains will continue to persist in spite of the rapid growth of the organized and formal milk marketing chains [14].

Most of the consumers under study $79.8 \%$ favored fresh raw milk over processed milk for their belief in its high quality compared to $20.2 \%$ who favored fresh raw milk over processed milk due to its affordable price, a result that clearly indicates that milk quality is of high priority when taking purchase 
decision. Impressively more than half of respondents under study $50.8 \%$ used stainless steel containers when purchasing raw milk compared to $33.1 \%$ who used plastic containers, a result that indicates a considerable level of awareness regarding food safety that can be further increased via strong extension services. Quality of fresh raw milk is of high priority for consumers when making their purchase decision where more than half of respondents $69.8 \%$ assured such a result. Kumar and Babu [15] stated that consumers perceive the quality of milk and dairy products on several perspectives and not only based on senses where upon regarding product quality, consumers are interested in sensory attributes such as taste or aroma, health aspect, comfort attributes and process attributes. When analyzing processed milk profile purchasers; $61.5 \%$ of consumers indicated they trust raw milk quality and trust processed milk quality. $60.7 \%$ of respondents purchased based on product brand, $42.3 \%$ paid considerable attention to package label reading, and further $48.8 \%$ assured product brand is the most important item read on product label. These results indicate the strong influence of brands on consumer purchase decisions. Njazi et al. [16] in a study in Kosovo showed that $85.2 \%$ of consumers claimed that the date of product production is the factor that mostly cares consumers when buying milk and dairy products, followed by the product composition, whereas brand and the origin of the product were of no particular attention to consumers when buying milk and dairy products. Table 2 .

Table-2: Fresh milk and processed milk purchase profile

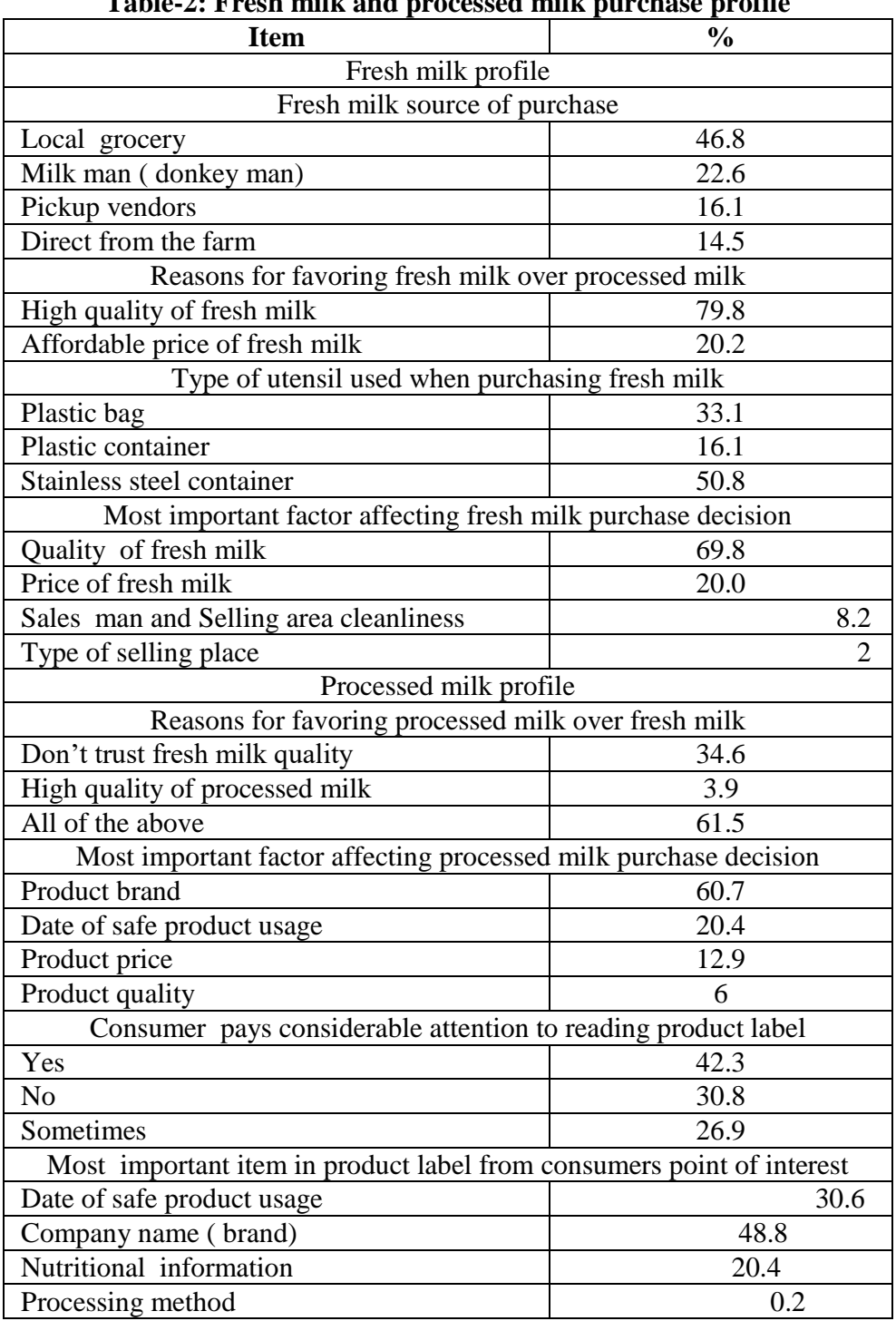

Upon studying consumer after purchase behavior for product treatment impressively all respondents $100 \%$ paid considerable attention to treatment measures from sieving, boiling etc. and such a result reveals that consumers are keen to perform food safety measures to protect their families. Consumers in modern world have become more concerned about health and food issues [17]. In developed countries, factors such as care for healthiness and environmental issues play an increasingly important role in food 
choice [18]. When it comes to consumers knowledge regarding information about processed milk manufacture $48.7 \%$ indicated they have no enough knowledge compared to only $2 \%$ who owned such information, this result raises a clear fact that food culture is of high effect on purchase decision in addition to poor promotion quality of companies that should contain more nutritional and processing information about products, especially as $46.7 \%$ of respondents indicated they don't trust promotional campaigns regarding processed milk quality and safety.

As for experiencing health issues after milk consumption $80 \%$ of respondents didn't experience medical issues, and for those encountering such issues $79.9 \%$ assured it was from processed milk, a fact that could need more research to prove such an issue. When addressing consumer measures taken after encountering health issues from milk consumption $43.3 \%$ stated they changed the place where they usually bought milk from in comparison to $40 \%$ who changed type of milk they consumed, such results clearly indicate the need for extension services that could fulfill consumers' food safety awareness measures. In a study in Khartoum, Barakat [19] found that that raw milk might cause hazards for human if it is consumed without pasteurization or heat treatment, it was recommended to develop a program such as establishment of HACCP system for milk production, handling and dispatch.

As for Consumer satisfaction level considering safety and quality of milk in Khartoum state, $50.7 \%$ of respondents assured they were not satisfied, moreover $65.3 \%$ suggested intensifying control over dairy farms for raising level of safety and quality of milk. Such a result calls for more action from governmental authorities regarding food safety measures to gain consumer trust. In china food processors initially sought HACCP certification to access export markets, HACCP is rapidly being adopted for domestic products and HACCP logos have begun to appear on labels in China, where consumers after receiving information on HACCP were willing to pay a modest price premium for HACCP-certified products, products with HACCP labels in Beijing supermarkets sold at a price premium of about $5 \%$ over products without such labels, holding other product attributes constant [20]. In Sudan several researchers reported the importance of milk in public health and that because of prevalence of some communicable diseases of milk and spoilage of this perishable product sanitary standards regulating milk production and marketing should be established for improvement of milk hygiene and quality [21, 22].Table 3.

Table-3: Consumer awareness concerning food safety measures and regulations

\begin{tabular}{|c|c|}
\hline Item & $\%$ \\
\hline \multicolumn{2}{|c|}{ Consumer pays considerable attention to product treatment after purchase (sieving, boiling etc.) } \\
\hline Yes & 100 \\
\hline No & 0.0 \\
\hline \multicolumn{2}{|c|}{ Consumer owns enough information about processed milk production and processing } \\
\hline Yes & 2.0 \\
\hline No & 48.7 \\
\hline To some extent & 49.3 \\
\hline \multicolumn{2}{|c|}{ Level of consumer trust on promotional campaigns regarding processed milk quality and safety } \\
\hline Yes & 15.3 \\
\hline No & 46.7 \\
\hline To some extent & 38.0 \\
\hline \multicolumn{2}{|c|}{ Occurrence of health issues after milk consumption } \\
\hline Had heath issues & 20 \\
\hline Didn't have medical issues & 80 \\
\hline \multicolumn{2}{|c|}{ Type of milk that caused health issues } \\
\hline Fresh milk & 20.1 \\
\hline Processed milk & 79.9 \\
\hline \multicolumn{2}{|c|}{ Actions taken by consumer upon encountering health issues } \\
\hline Stopped consuming milk & 16.7 \\
\hline Changed place of milk purchase & 43.3 \\
\hline Changed type of milk purchased & 40 \\
\hline \multicolumn{2}{|c|}{ Consumer satisfaction level considering safety and quality of Milk in Khartoum state } \\
\hline Satisfied & 12.0 \\
\hline Not satisfied & 50.7 \\
\hline To some extent & 37.3 \\
\hline \multicolumn{2}{|c|}{ Consumer suggestions for raising level of safety and quality of Milk in Khartoum state } \\
\hline Intensifying control over Dairy farms & 65.3 \\
\hline Setting food safety regulations & 15.7 \\
\hline Extension campaigns that target citizens & 19.0 \\
\hline
\end{tabular}


Table-4: Chi- square values of consumer education level effect

\begin{tabular}{|l|c|}
\hline \multicolumn{2}{|c|}{ Item2 } \\
\hline \multicolumn{2}{|c|}{ Consumer education level } \\
\hline Type of milk purchased & 0.63 \\
\hline Place of milk purchase & 0.470 \\
\hline Type of utensils used & 0.299 \\
\hline Product label reading & 0.891 \\
\hline
\end{tabular}

Chi- square values were deducted to evaluate the effect of consumer education level over several parameters that could affect consumer purchasing decision. Where P.values were 0.63 for type of milk purchased; 0.47 for place of purchase; 0.2 for type of utensils used for raw milk purchase; 0.89 for processed milk product label reading; all $\mathrm{P}$. values being more than 0.05 indicating non-significant effect of education level on all parameters under study. Such a result is a strong indication that food culture could be of more prominent effect on consumer purchase decision when it comes to milk. Şendur \& Atabek [23] stated that consumers mostly develop perceptions regardless of their socio-demographic differences due to the mainstreaming effect of mass media; however, a cluster analysis showed that younger more educated, wealthier and regular dairy consumers have lower levels of negative perceptions about milk, cheese and yogurt. Ates and Ceylan [24] also reported that milk freshness and packaging were important factors for urban consumers with secondary and above level education and with high level of income. More recently, Konar et al. [25] also found similar results that urban consumers from high socio-economic status group are more informed about the health risks of street (open) milk. Table 4.

\section{Conclusion}

Milk is considered an important everyday consumable commodity in most Sudanese households specially being a main source of nutrient; thus more effort is to be performed in understanding consumer perceptions and preferences to enable policy makers and dairy industry players to make practical decisions that could leverage food safety awareness programs to avoid hazards and risks associated with contaminated milk and milk products consumption hence insuring a healthy society.

\section{REFERENCES}

1. FAO. (2004). The Role of Post-Harvest Management in Assuring the Quality and Safety of Horticultural Produce. FAO Agricultural Services Bulletin, No: 152, Rome/Italy.

2. Badrie, N., Gobin, A., Dookeran, S., \& Duncan, R. (2006). Consumer awareness and perception to food safety hazards in Trinidad, West Indies. Food control, 17(5), 370-377.
3. Grunert, K. G. (2005). Food quality and safety: consumer perception and demand. European review of agricultural economics, 32(3), 369-391.

4. Ragaert, P., Verbeke, W., Devlieghere, F., \& Debevere, J. (2004). Consumer perception and choice of minimally processed vegetables and packaged fruits. Food quality and preference, 15(3), 259-270.

5. Lobb, A. E., Mazzocchi, M., \& Traill, W. B. (2007). Modelling risk perception and trust in food safety information within the theory of planned behaviour. Food quality and preference, 18(2), 384-395.

6. Roitner-Schobesberger, B., Darnhofer, I., Somsook, S., \& Vogl, C. R. (2008). Consumer perceptions of organic foods in Bangkok, Thailand. Food policy, 33(2), 112-121.

7. Van Rijswijk, W., \& Frewer, L. J. (2008). Consumer perceptions of food quality and safety and their relation to traceability. British Food Journal.

8. Redmond, E. C., \& Griffith, C. J. (2004). Consumer perceptions of food safety risk, control and responsibility. Appetite, 43(3), 309-313.

9. Imram, N. (1999). The role of visual cues in consumer perception and acceptance of a food product. Nutrition \& Food Science.

10. Rimal, A., Fletcher, S. M., McWatters, K. H., Misra, S. K., \& Deodhar, S. (2001). Perception of food safety and changes in food consumption habits: a consumer analysis. International Journal of Consumer Studies, 25(1), 43-52.

11. Yeung Ruth, M. W., \& Morris, J. (2001). Food Safety Risk: Consumer Perception and Purchase Behavior. British Journal of Food, 103(3), 170186.

12. Schifferstein, H. N., \& Cleiren, M. P. (2005). Capturing product experiences: a split-modality approach. Acta psychologica, 118(3), 293-318.

13. Fawi, N. M. T., \& Abdalla, M. O. M. (2013). Milk preferences of consumers and effect of the marketing mix on consumers' purchase decision of dairy products. Indian Journal of Marketing, 43(2), 57-62.

14. Kumar, A., \& Staal, S. J. (2010). Is traditional milk marketing and processing viable and efficient? An empirical evidence from Assam, India. Quarterly Journal of International Agriculture, 49(892-201665213), 213-225.

15. Kumar, A. A., \& Babu, S. (2014). Factors influencing consumer buying behavior with special reference to dairy products in Pondicherry state. International Monthly Refereed Journal of Research in Management and Technology,3(1), 65-73.

16. Bytyqi, N., Muji, S., \& Rexhepi, A. (2020). Consumer Behavior for Milk and Dairy Products as Daily Consumption Products in Every Household-The Case of Kosovo. Open Journal of Business and Management, 8(02), 997. 
17. Morrison, J. (2008). International Business: Challenges in a Changing World. Palgrave Macmillan.

18. Gracia, A., \& Albisu, L. M. (2001). Food consumption in the European Union: main determinants and country differences. Agribusiness: an international journal, 17(4), 469-488.

19. Barakat, E.A. (1995). Evaluation of milk hygiene in Khartoum State -Sudan.

20. Wang, Z., Mao, Y., \& Gale, F. (2008). Chinese consumer demand for food safety attributes in milk products. Food policy, 33(1), 27-36.

21. Yagoub, S. O., Awadalla, N. E., \& El Zubeir ${ }^{\circ}$, I. E. (2005). North (Sudan) and Their SusCeptibility to Antimicrobial Agents. Journal of Animal and Veterinary Advances, 4(3), 341-344.
22. Elmagli, A. A. O., Ibtisam, E. M., \& Zubeir, E. L. (2006). Study on the hygienic quality of pasteurized milk in Khartoum State (Sudan). Research Journal of Animal and Veterinary Sciences, 1(1), 12-17.

23. Atabek, G. Ş., \& Atabek, Ü. (2019). Consumer perceptions towards dairy products: effects of mass media. Online J Commun Media Technol,9(2), e201908.

24. Ates, H. C., \& Ceylan, M. (2010). Effects of socioeconomic factors on the consumption of milk, yoghurt, and cheese. British Food Journal.

25. Konar, N., Haspolat K.I., Dalabasmaz, S., Poyrazoğlu, E. S., \& Artık, N. (2014). Street milk and urban consumers in Turkey: a descriptive study. Journal of Consumer Protection and Food Safety, 9: 23-35. https://doi.org/10.1007/s00003013-0854-8 